\title{
A escuta de crianças vítimas de abuso sexual intrafamiliar na concepção de profissionais que atuam no âmbito do Judiciário
}

(Listening to children victims of sexual abuse in the family context according to professionals of the Judiciary System)

(El saber escuchar a los niños victimas de abuso sexual intrafamiliar desde el punto de vista de los profesionales que actúan en el ámbito del poder judicial)

\author{
Janaina Perty Fröner* \\ Vera Regina Röhnelt Ramires*
}

\begin{abstract}
Resumo
O objetivo desta pesquisa foi analisar as concepções de profissionais da área da saúde e operadores do Direito a respeito da escuta das crianças que experimentaram abuso sexual intrafamiliar. Foi realizado um estudo descritivo transversal, utilizando-se a técnica de entrevista individual semiestruturada para coleta de dados e análise de conteúdo para análise dos dados. Participaram 15 profissionais da área da saúde e operadores do Direito. Os resultados apontaram para a existência de limitações na escuta da criança no âmbito do Judiciário e para o despreparo dos profissionais para realização dessa escuta. Identifica-se uma tensão entre as necessidades da criança e as demandas do Judiciário com relação à constituição da prova e responsabilização do agressor. Conclui, salientando a importância do trabalho interdisciplinar.
\end{abstract}

Palavras-chave: escuta de crianças; abuso sexual; Judiciário; interdisciplinaridade.

\begin{abstract}
The goal of this study was to analyze the conceptions of Health Professionals and Law Operators of the Judiciary System in what concerns listening to children who have suffered sexual abuse in the family context. A transversal descriptive study was carried out, using semi-structured individual interviews for data collection and content analysis. The participants were fifteen Health Professionals and Law
\end{abstract}

\footnotetext{
Mestra em Psicologia pela Unisinos, especialista em Psicoterapia Psicanalítica e Violência Doméstica - Unisinos. E-mail: jpfroner@brturbo.com.br.

** Doutora em Psicologia Clínica pela PUC SP, professora, pesquisadora e coordenadora do Programa de Pós-graduação em Psicologia da Universidade do Vale do Rio dos Sinos - Unisinos. E-mail: veraramires@terra.com.br.
} 
Operators. The results indicated limitations in listening to the child in the judiciary context, as well as professionals unprepared for the task. There is a tension between the child's needs and the judiciary's demands in relation to the collection of evidence and the offender's accountability. We conclude stressing the importance of interdisciplinary work.

Key words: Listening to children; Sexual abuse; Judiciary System; Interdisciplinarity.

\section{Resumen}

Este estudio tuvo como objetivo examinar las concepciones de escuchar a los niños que han sufrido abuso sexual intrafamiliar acuerdo con los profesionales en el área de Salud y los operadores de la ley que actúan en el seno del Poder Judicial. Se realizó un estudio descriptivo transversal, mediante la técnica de entrevista semi-estructurada para la recolección de los datos y el análisis de contenido para el análisis de los datos. Los participantes fueron 15 profesionales en el área de Salud y los operadores de derecho. Los resultados apuntan a la existencia de limitaciones en la escucha del niño en el poder judicial y la falta de preparación de los profesionales para lograr esta escucha. Se identifica una tensión entre las necesidades del niño y las demandas del Poder Judicial en relación con la recogida de pruebas y la responsabilidad del delincuente. Se concluye destacando la importancia del trabajo interdisciplinario.

Palabras clave: escucha de niños; el abuso sexual; poder judicial; interdisciplinariedad.

\section{Introdução}

0

objetivo deste estudo foi analisar as concepçóes de escuta de crianças vítimas de abuso sexual intrafamiliar apresentadas por profissionais da área da saúde e operadores do Direito que atuam no âmbito do Judiciário. Por abuso sexual intrafamiliar compreende-se um conjunto de atitudes que envolvem poder, coação e, ou, sedução e pode variar entre ações com ou sem contato sexual, perpetrado geralmente por familiares ou pessoas que tenham um vínculo significativo com a criança, sem necessariamente haver laço de consanguinidade (Araújo, 2002; Azambuja, 2005; Barbosa, 2007; Dias, 2007; Ferreira, 2005; Sanderson, 2005). O agressor busca ou obtém uma gratificação e satisfação sexual com crianças ou adolescentes, logo em processo de desenvolvimento, em atividades sexuais que não compreendem em sua totalidade, para as quais não estão aptos a concordarem e que violam as regras sociais e familiares de nossa cultura. 
Uma característica particular dessa forma de violência, também conhecida como incesto, é a dependência afetiva e o laço de confiança existente entre vítima e abusador, gerando sentimentos contraditórios na criança e a cronificação da atitude incestogênica, que se torna um segredo permanente no seio da família (Dias, 2007; Dobke, 2001; Pfeiffer \& Salvagni, 2005). O abuso sexual intrafamiliar pode implicar em uma desestruturação de toda a organização social e psíquica da família (Araújo, 2002; Ferreira, 2005; Junqueira, 2002).

Além de dificuldades no desenvolvimento, essa forma de violência deixa vestígios, principalmente na saúde mental (Ghetti, Alexander, \& Goodman, 2002; Sanderson, 2005). O abuso sexual, na maior parte dos casos, não deixa marcas no corpo da criança e, por esse motivo, há dificuldades em decifrar ou avaliá-lo.

O que gera mais obstáculos para os profissionais na escuta da criança vítima de abuso é que, além de ela apresentar um intenso sofrimento em virtude do impacto e do trauma experimentado, a possibilidade da revelação ou "quebra da síndrome do silêncio" é sentida como mais um momento árduo, atravessado por muitos sentimentos e emoçōes de cunho ambivalente (Azambuja, 2006; Ferreira \& Schramm, 2000). Porém, enquanto o abuso sexual não for revelado ou descoberto, não há como proteger a criança de forma integral. Por outro lado, quando o abuso é evidenciado, outros dilemas e conflitos terão que ser enfrentados, dentro da família e na sociedade (Azevedo, 2001; Junqueira, 2002).

A ocorrência do abuso sexual intrafamiliar ou a suspeita dele, quando revelada, geralmente desencadeia um processo judicial, seja de natureza de medida de proteção, processo crime e/ou destituição do poder familiar. Operadores do Direito levam em consideração a Constituição Federal e o Estatuto da Criança e do Adolescente (ECA) para garantir a proteção integral das crianças e dos adolescentes, além de buscarem a justiça diante dos fatos. A criança usualmente participa dos processos como única testemunha e vítima do delito sexual, muitas vezes anos após o ocorrido, sendo ouvida pelos profissionais da Área da Saúde e, ou, pelos Operadores do Direito (Azambuja, 2006; Brito, Ayres, \& Amendola, 2006; Daltoé-Cezar, 2007; Dias, 2007; Dobke, 2001; Juárez-López, 2004).

\section{A escuta da criança no âmbito do Judiciário}

A legislação garante direitos fundamentais ao cidadão e isso inclui as crianças, que não podem ter sua experiência rejeitada (Daltoé-Cezar, 2007; Dobke, 2001). O espaço do Judiciário tem características singulares, uma 
vez que usa um conjunto de medidas que visam à objetividade e à solução do problema, nem sempre indicado às crianças que estão em pleno processo de desenvolvimento (Azambuja, 2006; Colacique, 2006; Dobke, 2001). Os autores são unânimes ao reconhecerem a necessidade de cuidados especiais na oitiva da criança vítima de abuso sexual intrafamiliar durante a aferição de provas, sendo essa uma das demandas do Sistema Judiciário. Dependendo de como é realizado o atendimento da criança nessa esfera, ele poderá causar traumas adicionais tão graves quanto os do abuso sexual em si (Araújo, 2002; Azambuja, 2006; Azevedo, 2001; Dobke, 2001; Ghetti, Alexander \& Goodman, 2002; Ward, 2003).

Benfica e Souza (2002), Ferreira (2007) e Azambuja (2006) sugerem que a criança traumatizada e em sofrimento não precisa ser inquirida em juízo, referindo que não existe nenhum parágrafo no princípio constitucional brasileiro apontando para essa obrigatoriedade. Neste sentido, Thèry, citada por Brito, Ayres e Amendola (2006), considera que, ao exercer o direito de testemunhar (responsabilidade civil e capacidade jurídica), a criança perde o direito à infância, exercendo funções que são de responsabilidade dos adultos. A autora sugere uma maior participação da família nos processos, para zelar pelos direitos da criança. Nessa mesma direção, vem sendo postulado que, quando a criança não deseja falar sobre o abuso, pode indicar um adulto de sua confiança que relatará o ocorrido (Barbosa, 2007; Brito, Ayres \& Amendola, 2006; De San Lazaro, 1995; Ferreira, 2005).

Pesquisas sobre as formas de atendimento e necessidades da criança que sofreu abuso sexual propõem que ela deve ser acolhida em ambiente seguro e adequado, por um profissional capacitado para compreender suas demandas, que são as de um ser em desenvolvimento, abalada pela experiência do abuso (Azambuja, 2006; Azevedo, 2001; Daltoé-Cezar, 2007; Dobke, 2001; Junqueira, 2002). O profissional deve levar em consideração a tensão psíquica resultante do abuso e promover intervenções que possibilitem uma elaboração do seu impacto sobre o estado emocional da criança.

Para garantir o melhor interesse da criança, a literatura propóe que, durante sua escuta, a forma de ela se expressar e até mesmo seu silêncio devam ser compreendidos e respeitados incondicionalmente (Barbosa, 2007; Heiman \& Ettin, 2001; Pfeiffer \& Salvagni, 2005). A confiança nos adultos, perdida em virtude da dinâmica do abuso e suas particularidades, deve ser resgatada pelo profissional por meio de um vínculo seguro (Azevedo, 2001; Dobke, 2001; Goodman, Bottoms, Rudy, Davies \& Schwartz-Kenney, 2001; Juárez-López, 2004; Junqueira, 2002; Pfeiffer \& Salvagni, 2005). É recomendado deixar a criança falar livremente ou usar perguntas abertas, com linguagem acessível, 
possibilitando respostas com maior e melhor conteúdo. Jogos, brinquedos de forma geral, desenhos e instrumentos projetivos são destacados pelos autores para superar as habilidades verbais limitadas das crianças, assim como para auxiliar na avaliação e diagnóstico.

Considerando as demandas do Judiciário e as necessidades da criança, muitos países já criaram uma lei especial que prioriza o atendimento da criança vítima de abuso sexual com maior proteção durante a constituição da prova, evitando, por exemplo, sua inquirição direta pelo juiz de Direito e pelas partes (Daltoé-Cezar, 2007; Juárez-López, 2004). No Brasil não há nada diferente dos padrões tradicionais, em forma de lei, que considere as condiçôes especiais da criança; idade, maturidade e sofrimento emocional proveniente da agressão sofrida (Azambuja, 2006; Benfica \& Souza, 2002; Daltoé-Cezar, 2007; Dobke, 2001). Há um Projeto de Lei que tramita no Senado Federal (PLC 35/2007) para que o depoimento da criança seja colhido no formato do chamado "depoimento sem dano", DSD (Daltoé-Cezar, 2007). Nessa abordagem, o profissional da área da saúde utiliza pontos no ouvido e traduz ou decodifica para a criança, em sala diferenciada, o que o juiz e os advogados querem saber. Autoridades judiciais e as partes permanecem na sala de audiências, assistindo pela televisão à inquirição.

Essa modalidade de oitiva da criança, criada no Juizado da Infância e Juventude de Porto Alegre, em 2003, por Daltoé-Cezar (2007), tem suscitado um intenso debate (Aleixo, 2008; Brito, 2008; Conselho Federal de Psicologia, CFP, 2008a, 2008b). Entendem esses autores que, a despeito da intenção de proteção dos direitos da criança, essa iniciativa implica o risco de colocá-la no lugar de objeto do Direito e não deveria ser impositiva. Ao contrário, à criança deveria ser garantido o direito de falar somente se assim o desejasse.

Além disso, para o CFP (2008a), Aleixo (2008) e Brito (2008) tal tarefa não corresponde àquela do psicólogo, a quem não cabe colher testemunhos ou realizar audiências. Escutar a criança, acolhendo-a efetivamente com relação às suas demandas, é diferente de colher seu depoimento visando à aferição de provas e à punição do agressor, muitas vezes alguém com quem a criança também mantém laços afetivos. Salientam ainda os autores que o DSD pode sim provocar danos na criança, revitimizando-a.

Assim como ocorre no Projeto desenvolvido no Rio Grande do Sul, alguns autores consideram importante que a entrevista seja sempre registrada audiovisualmente. Dessa forma, o conteúdo gravado em DVD servirá de 
subsídio para análise do profissional que avalia a situação, auxiliando na prova do processo judicial, além de evitar exposição da criança em novas entrevistas ou depoimentos (Daltoé-Cezar, 2007; Juárez-López, 2004).

$\mathrm{Na}$ condição de perito-avaliador, diferente da oitiva em depoimento, o profissional da área da saúde, que pode ser o médico, especialmente o pediatra e, ou, o psiquiatra, o assistente social, o psicólogo, tem a vantagem de dispor de um tempo maior para formação de um vínculo de confiança com a criança e para respeitar o seu ritmo, sem correr o risco de pressioná-la e, ou, de rejeitar sua experiência traumática. Com formação adequada para isso, poderá fazer uma avaliação mais aprofundada, com a possibilidade de compreender conteúdos latentes da dinâmica do caso, traduzindo para o juiz de Direito o que for do melhor interesse da criança, garantindo sua proteção integral (Azambuja, 2006; Ferreira, 2007; Junqueira, 2002). Os subsídios oferecidos por esse tipo de avaliação poderão ser um diferencial no momento em que o magistrado necessita concluir o julgamento do caso, podendo chegar à responsabilização do agressor sexual (Azevedo, 2001; Cesca, 2004; Rovinski, 2004).

Profissionais da área da saúde e operadores do Direito, portanto, com suas formaçōes distintas e complementares, atuando em conjunto, podem favorecer um olhar interdisciplinar sobre a criança e suas necessidades (Alonso-Quecuty, 1999). Essa escuta operacionalizada por distintas áreas do conhecimento deve ocorrer em sintonia, de forma articulada, em um contexto no qual estejam claramente definidos e respeitados os limites de cada uma (Aded, Dalcin, Moraes \& Cavalcanti, 2006; Azambuja, 2005; Brito, Ayres \& Amendola, 2006; Habigzang, Azevedo, Koller \& Machado, 2006; Pfeiffer \& Salvagni, 2005).

Destaca-se o quanto é complexo e peculiar escutar as crianças no âmbito do Judiciário, garantindo sua proteção integral e, ao mesmo tempo, respeitandoas em relação às consequências de uma experiência traumática. Sendo assim, justifica-se o presente estudo, que buscou compreender como os profissionais da área da saúde e os operadores do Direito concebem a escuta da criança vítima de abuso sexual no contexto do Sistema Judiciário.

\section{Método}

Foi realizado um estudo descritivo, transversal, pautado pela abordagem qualitativa de pesquisa. Os participantes foram 15 profissionais da área da saúde e operadores do Direito que atuam no âmbito do Sistema Judiciário, ou a serviço dele, no atendimento de crianças vítimas de abuso 
sexual, especialmente intrafamiliar: um pediatra; dois assistentes sociais; seis psicólogos; três promotores da infância e juventude; um juiz da infância e juventude; um delegado de polícia e um advogado. Desses, onze participantes são do sexo feminino e quatro do masculino. Cinco deles possuem entre $31 \mathrm{e}$ 39 anos de idade; oito, entre 40 e 49 anos, e dois com 50 anos ou mais. Em relação à sua formação, sete participantes têm mais de 20 anos de formados e apenas dois deles, menos de 10 anos. Quatorze têm o título de especialista. seis participantes fizeram ou estão concluindo mestrado e um deles concluiu doutorado. Todos tem experiência significativa com casos de abuso sexual intrafamiliar (mais de 10 anos de experiência), tendo atendido entre dezenas e centenas de casos.

Os participantes foram acessados por conveniência e contatados em cinco cidades do Estado do Rio Grande do Sul. O número exato de participantes não foi definido a priori, utilizando-se o critério de saturação dos dados para a finalização das entrevistas.

\section{Procedimentos de coleta e análise dos dados}

Para a coleta dos dados, foi utilizada a técnica de entrevista individual semiestruturada. As entrevistas foram realizadas no contexto do Fórum, dos consultórios médico ou psicológico, ou escritório do advogado. Foram gravadas e posteriormente transcritas, sob autorização. Cada entrevista foi baseada em questôes norteadoras que buscaram identificar as concepçôes de escuta da criança que sofreu abuso sexual, de acordo com os profissionais.

A análise das entrevistas foi baseada no método de análise de conteúdo (Minayo, 1998). Foram estabelecidas categorias analíticas, com base na revisão bibliográfica, visando a identificar: "a prática dos profissionais no que diz respeito à escuta de crianças vítimas de abuso sexual", suas "concepções dessa escuta", as "dificuldades da escuta de crianças vítimas de abuso sexual" e o "papel do trabalho interdisciplinar". Com base nas categorias analíticas, chegou-se às categorias empíricas, organizando-se o material obtido por meio de etapas sucessivas. Para complementar os dados obtidos nas entrevistas, foi utilizada uma ficha informativa sobre a experiência do profissional entrevistado.

O projeto de pesquisa foi avaliado e aprovado pelo Comitê de Ética em Pesquisa da universidade a qual se vinculam as pesquisadoras. Os participantes foram informados sobre o estudo e seus procedimentos e assinaram o termo de consentimento livre e esclarecido. 


\section{Resultados e discussão}

A análise das entrevistas permitiu o estabelecimento de cinco categorias: "dinâmica própria do abuso sexual", "preparo e capacitação do profissional", "necessidades da criança", "demandas do Judiciário" e "importância do trabalho interdisciplinar". Partiu-se das categorias analíticas definidas a priori e descritas acima, levando-se em consideração a formação, a experiência e o contexto dos profissionais. As falas dos participantes foram inicialmente recortadas e agrupadas de acordo com o conteúdo e significado da fala em categorias intermediárias e, num movimento dialético, remetido, constantemente à teoria geraram as categorias finais. A seguir, apresenta-se e discute-se cada uma das categorias.

\subsection{Dinâmica própria do abuso sexual intrafamiliar}

De acordo com as concepções dos entrevistados, a dinâmica do abuso sexual intrafamiliar tem peculiaridades e características específicas, diferentes de outras formas de violência contra a criança e o adolescente. $\mathrm{O}$ abuso sexual intrafamiliar acaba sendo mais complexo e de difícil acesso aos profissionais, de acordo com os participantes, porque apresenta muitas variáveis emocionais, sociais e legais associadas. $\mathrm{Na}$ maioria das vezes o abuso não deixa marcas visíveis aos olhos, porém deixa sequelas para o desenvolvimento da criança e gera uma desorganização psicossocial em toda a família. Tanto os profissionais da área da saúde quanto os operadores do Direito consideram que o vínculo existente entre o abusador e a criança promove um pacto de silêncio e segredo, tornando essa experiência uma forma natural de relacionamento durante muitos anos, até que a vítima, na maioria das vezes na adolescência ou vida adulta, consegue perceber que essas atitudes não foram positivas para ela. A hipótese de que o ambiente familiar protege os seus membros mais vulneráveis é falha nesses casos e é justamente a dependência afetiva e o laço de confiança que mascaram o abuso, gerando sentimentos confusos e ambivalentes.

Diferentemente de outras formas de violência, o abuso intrafamiliar, muitas vezes, fixa a criança em uma posição de passividade. Além disso, torna-se de certa forma responsável pela manutenção dos vínculos, mesmo que estes não sejam os mais adequados. A criança também é responsabilizada quando, ao relatar o abuso sexual, faz a quebra do contrato informal que mantém a família em suas funções, desde as estruturais, econômicas e também dos papéis de cada um, por isso a dificuldade da quebra do segredo. Como afirmam os participantes: 
[...] Eu acho que a situação é mais difícil quando a suspeita é intrafamiliar, porque existe uma relação de afeto muito forte entre abusado e abusador, o segredo é um pacto de silêncio travado entre duas pessoas que se amam, então é muito mais difícil [...] (médicopediatra);

[...] Por fim, ao sair da audiência, a menina se abraçou no pai e começou a chorar [...] Como que essa vítima abusada pelo pai há tantos anos, estava demonstrando afeto com ele, estava tentando se retratar para protegê-lo (promotora de justiça).

Contudo, igualmente mobilizada está a família, que necessita acionar suas defesas, muitas vezes evitando enxergar o abuso como um problema, para lidar com todas as conflitivas envolvidas no fenômeno. Torna-se importante tranquilizar o familiar protetor, orientá-lo para possuir uma vigilância maior e auxiliá-lo na construção de uma rede de apoio. Nesse sentido, principalmente os profissionais da área da saúde, mas também os especialistas da área Jurídica consideram fundamental estender a escuta e assistência a familiares e terceiros. Para tanto, quem tem um vínculo afetivo adequado com a criança é que pode fomentar a possibilidade de haver proteção, rompendo com a dinâmica patológica do abuso sexual e organizando a escuta e a quebra do segredo, segundo os entrevistados:

[...] Nós evitamos o máximo possivel a oitiva, especialmente de crianças, buscando nesses casos informaçōes de terceiros. (promotor de justiça).

[...] A gente precisa identificar um outro familiar né, mas principalmente a identificação de uma pessoa de confiança da criança, isso é o mais importante (assistente social).

Em relação à escuta de familiares e terceiros, alguns autores sugerem que, para evitar uma maior exposição da criança e não causar traumas adicionais a ela, os adultos próximos à criança ou envolvidos na situação abusiva, como o próprio abusador, podem ser escutados para a constituição de provas em depoimentos ou na participação em perícias técnicas (Azambuja, 2006; Barbosa, 2007; Brito, Ayres \& Amendola, 2006; De San Lazaro, 1995; Ferreira, 2005; Ferreira, 2007). A literatura também aponta a importância de escutar os familiares da criança para receberem assistência adequada e orientações sobre as demandas sequenciais da revelação do abuso e proteção da criança (Azambuja, 2006; Pfeiffer \& Salvagni, 2005). Essa categoria encontra-se, portanto, em sintonia com a literatura, que indica nos casos de abuso sexual intrafamiliar, implicações e consequências importantes não apenas para a criança, mas para toda a família. 


\subsection{Preparo e capacitação do profissional}

De acordo com os operadores do Direito e os profissionais da área da saúde, há dificuldades, limitaçóes e falta de preparo para realizar o atendimento da criança vítima de abuso sexual intrafamiliar. De acordo com os participantes, esse atendimento necessita muito mais além da formação universitária de base. Somente o treino intelectual não é suficiente para atender eficazmente uma criança em sofrimento e que precisa revelar o abuso. De forma geral, todos os entrevistados não se sentem suficientemente preparados para realizar a escuta da criança e atender suas demandas e necessidades e registram que:

[...] Para muitas crianças o melhor teria sido nunca contar o segredo, porque os profissionais, a sociedade não estão preparados, não foram capazes de atendê-los quando elas procuraram auxílio. (Delegada de Polícia).

[...] É uma escuta difícil, mobiliza a gente, não estamos preparados o suficiente para essa escuta. (psicóloga).

De acordo com a maioria dos participantes, os operadores do Direito não possuem formação, preparação técnica e emocional para realizar a escuta da criança abusada sexualmente. Referem os participantes, incluindo os próprios operadores do Direito, que esses profissionais não têm condições para lidar especialmente com os sentimentos contraditórios apresentados pela criança durante a oitiva. Mencionam, porém, que eles têm buscado conhecimentos teórico-práticos para compreender melhor a dinâmica do abuso sexual intrafamiliar e, quando necessário, intervir. Os participantes assinalaram que:

[...] Nesta questão do abuso intrafamiliar existem dinâmicas que nós da área do Direito não compreendíamos, não sabíamos. (promotora de justiça).

[...] Pessoas que não têm a sensibilidade adequada pra perceber o quanto a criança está sofrendo e muitas vezes não conseguem por angústia própria, por falta de treinamento ou por dificuldades pessoais fazer a criança se sentir protegida ou acolhida (médico pediatra).

A capacitação continuada do profissional, assim como seu preparo emocional, permite uma melhor compreensão de seus limites pessoais e profissionais, assim como favorece uma escuta adequada da criança com seus processos psíquicos alterados em função do trauma do abuso. Essa capacitação pode fornecer ao profissional a possibilidade de transitar com maior segurança pelos conflitos e dificuldades de cada criança e seus familiares. 
A literatura aponta que a escuta da criança abusada sexualmente no cenário familiar exige preparação emocional e capacitação continuada do profissional que trabalha na defesa da sua proteção e dos seus direitos (Araújo, 2002; Azambuja, 2005; Azevedo, 2001; Daltoé-Cezar, 2007; Dobke, 2001; Junqueira, 2002). Autores como Daltoé-Cezar (2007), Morales e Schramm (2002), Lamb et al. (2003) afirmam que os operadores do Direito não têm preparo suficiente para aderir às recomendaçôes em relação à melhor escuta da criança sexualmente abusada e dar conta de suas necessidades. $O$ depoimento sem dano (Daltoé-Cezar, 2007) seria uma forma de superar a falta de preparo dos operadores do Direito para a inquirição de crianças. Porém coloca o psicólogo ou assistente social no exercício de um papel que não é o seu (Aleixo, 2008; Brito, 2008; CFP, 2008a, 2008b).

Portanto, de acordo com a categoria estabelecida, há a necessidade de capacitação e preparo dos profissionais para realizar essa escuta e garantir a proteção da criança, conduzindo o processo de maneira que traga menos prejuízo à sua vida.

\subsection{Necessidades da criança}

Pode se afirmar que, para os profissionais entrevistados, há uma compreensão de que a criança precisa ser escutada prioritariamente. Porém sua escuta não pode ser igualada a dos adultos, especialmente no âmbito do Judiciário. Seu nível de desenvolvimento emocional e cognitivo devem ser levados em consideração para que sejam evitadas novas formas de sofrimento no transcorrer do atendimento e a partir dele. Todos os participantes da pesquisa se posicionaram dessa forma, referindo-se à necessidade de cuidados que possibilitem menor angústia e condiçôes que facilitem a expressão espontânea da criança.

Os especialistas em saúde, de forma geral, mostraram-se mais mobilizados com a experiência vivenciada pela criança e com o seu sofrimento. Apontaram que a criança é respeitada e protegida integralmente quando sua escuta se dá através de perícias ou avaliaçōes psicológicas. O psicólogo, o médico ou o assistente social capacitado e preparado para realizar esse atendimento, quando realiza a escuta com zelo e postura sensível e acolhedora, de acordo com o nível de desenvolvimento, respeitando o ritmo da criança, garante proteção a ela. Já os profissionais do Direito consideram a escuta especializada do profissional da saúde facilitadora da fala infantil no depoimento ou inquirição no contexto do Sistema Judiciário, e, dessa, forma reafirmam a possibilidade de assegurar a proteção da criança, com a responsabilização e o afastamento do agressor. De acordo com os participantes: 
[...] Procuro respeitar o tempo da criança e a condição dela de se expressar. (Psicóloga);

[...] Eu digo que talvez uma avaliação pudesse ser melhor do que a escuta em forma de depoimento. Porque realmente em uma situação mais formal, a criança vai ter mais dificuldade. (Pediatra);

[...] Tem esse aspecto de proteção, de suspender a ação agressiva e de também buscar acompanhamento terapêutico, e a segunda característica é de prova, é de produzir uma prova que permita o desencadeamento dessa proteção. (Promotor de Justiça).

A importância de um ambiente adequado, seguro e lúdico, de acordo com as características infantis, foi igualmente lembrada pelos profissionais de ambas as áreas do conhecimento. A utilização de material gráfico e brinquedo livre é uma vertente orientadora para que a criança consiga se comunicar e expressar o que considera essencial, especialmente na escuta dos pré-escolares. Porém, principalmente os profissionais do Direito sugeriram evitar a escuta da criança que ainda não possua o "dom da palavra" no âmbito do Judiciário, em função das demandas que provêm dele.

Os dois grupos de profissionais mencionaram que essa intervenção, de qualquer forma, mobiliza sentimentos e emoções, como a vergonha, o medo e o sentimento de culpa, que devem ser acolhidos pelos técnicos que atendem no âmbito do Judiciário. Segundo os participantes:

[...] Nesses casos a gente procura criar um ambiente o mais receptível possível. (Promotor de Justiça).

[...] A dificuldade que eu vejo é na abordagem com criança pequena, e criança pequena que eu digo é desde que começa a falar, de 3, 4 aninhos até 5, 6. Porque de 6 pra frente a gente já consegue ter um relato com começo meio e fim. (assistente social).

Essas concepções expressadas pelos profissionais recebem amparo da literatura científica. Em relação ao ambiente, os autores referem que ele deve ser seguro, tranquilo e acolhedor da dor e sentimentos despertados na criança, com disposição de material lúdico para a expressão da sua experiência (Daltoé-Cezar, 2007; Juárez-López, 2004; Junqueira, 2002; Pfeiffer \& Salvagi, 2005). A limitação verbal das crianças menores pode ser sanada por material correspondente ao universo infantil. Todavia, devido ao nível cognitivo e emocional em que se encontram, as crianças podem apresentar menor compreensão dos fatos e maior facilidade de serem sugestionadas (Dobke, 
2001; Goodman, Bottoms, Rudy, Davies \& Schwartz-Kenney, 2001; JuárezLópez, 2004; Pfeiffer \& Salvagni, 2005).

A criança que sofreu abuso sexual traz consigo uma vulnerabilidade em relação ao vínculo de confiança com o adulto (Azambuja, 2006; Azevedo, 2001; Dobke, 2001; Junqueira, 2002; Ferreira, 2005; Ferreira, 2007). Por isso, o profissional tem papel fundamental no manejo da reconstrução das condições para essa escuta, de acordo com os participantes:

[...] O que é mais importante é esse estabelecimento do vínculo de confiança com a criança, porque deve ser algo muito horrível, chegar na frente de uma pessoa que nunca se viu e ter que relatar logo uma experiência abusiva que é dolorosa pra criança. (Promotora de Justiça);

[...] Mas a gente vai trabalhando, vai estabelecendo a questão da confiança, vai explicando que está ali para ajudar, então aos poucos, através de desenhos, jogos, brinquedos, a gente percebe as situaçóes que ela vai representando [...] (psicóloga).

Foi salientado pelos profissionais da saúde a importância de situar a criança diante dos procedimentos pelos quais ela irá passar no âmbito do Judiciário, o que está diretamente ligado com a confiança que a criança está tentando desenvolver em relação ao profissional (Azambuja, 2006; Azevedo, 2001; Ferreira, 2005; Junqueira, 2002; Pfeiffer \& Salvagni, 2005). Os profissionais têm o dever de explicar para a criança qual a sua função nessa escuta, conforme expressa uma psicóloga entrevistada:

[...] Eu início por ter uma compreensão de até que ponto para criança tá claro o que ela veio fazer, o que tá acontecendo, né. Isso é seguido assim, então de uma explicação de qual é o meu papel, quem eu sou, por que a criança tá ali (psicóloga).

Além disso, profissionais da Saúde revelam que a criança apresenta a necessidade de um cunho terapêutico que forneça sustentação psíquica e afetiva na revelação ou quebra do segredo.

Já os operadores do Direito acreditam que, oferecendo espaço no âmbito do Judiciário não se rejeita a experiência da criança enquanto sujeito de direitos, além de identificar a autoria do abuso e a responsabilização deste (Daltoé-Cezar, 2007; Dobke, 2001; Juárez-López, 2004). Porém, capacidade ou incapacidade de representação infantil pela verbalização, o brincar, o silêncio ou outras formas de expressão, anulam-se ou são irrelevantes diante do objetivo de averiguar provas e evidências claras do 
abuso sexual (Azambuja, 2006; Azevedo, 2001; Benfica \& Souza, 2002; Ferreira, 2007; Junqueira, 2002).

Como vimos acima, atender a criança nas suas demandas e necessidades deveria ser a prioridade sempre, e esta premissa está na origem da crítica feita ao depoimento sem dano, quando privilegia a produção de provas e a punição do culpado, em detrimento da proteção do estado e do bem-estar da criança (Aleixo, 2008; Brito, 2008; CFP, 2008a, 2008b).

\subsection{Demandas do Judiciário}

Tanto entre os profissionais da saúde como para os do Direito, essa categoria ficou evidenciada. Porém foi construída de forma distinta entre os participantes dos diferentes grupos. As demandas do Judiciário aparecem tanto nas audiências judiciais e inquéritos policiais, como na perícia realizada pelo profissional da saúde.

Os entrevistados reconhecem que algumas necessidades da criança entram em contradição com as demandas da ordem do Judiciário. Apesar dos profissionais buscarem um melhor preparo para evitar sofrimentos secundários à criança, durante esses procedimentos, o rito jurídico e o processo da maneira como ocorre pode ser doloroso para ela. Nessa categoria, os profissionais da área da saúde entrevistados destacaram que as demandas do Judiciário interferem, muitas vezes, no trabalho efetivo de busca de proteção da criança.

Esses profissionais salientaram a exigência de indícios fortes de autoria, já na Polícia Civil, para dar continuidade ao processo nas duas Instâncias: promover ações de proteção em favor da criança na Vara da infância e juventude e efetivar-se a prova material na área do Crime para atribuição de culpa. Também na área da saúde existe essa atribuição, porém esse entendimento fica subordinado às necessidades da criança, como sua proteção integral, na concepção desse grupo profissional. Alguns exemplos ilustram isso:

[...] Eu já peguei processos em que a criança simplesmente não falou nada. Pra nós do Direito, não falar significa uma não prova, não serviu de prova. (promotor de justiça);

Se tu não chega na condenação do réu através da avaliação, então essa criança precisa ser ouvida em audiência. (Psicóloga).

Para constituir a prova judicial os operadores do Direito e os profissionais da área da saúde precisam se adequar a alguns ritos jurídicos, tanto na inquirição da criança como em sua avaliação técnica (perícia). Os profissionais que 
se disponibilizam para esse trabalho no âmbito do Judiciário reconhecem o importante papel desse sistema para a criança e a sociedade em geral, porém, se questionam em relação à sua rigidez, como se observa nestas falas:

[...] É importante que fale, que verbalize... algumas vezes, eu fico convencida por outras questôes como pela brincadeira, por algumas coisas que a criança diz que não seja diretamente, mas não serve ajudar os órgãos responsáveis a dar algum encaminhamento né. (Psicóloga).

A Polícia Civil tem que formalizar uma prova, então a nossa sorte é quando a criança vem e consegue tranquilamente verbalizar isso. (delegada de Polícia).

No âmbito do Judiciário, a escuta recebe certa adaptação em relação às técnicas utilizadas pelos profissionais da área da saúde no atendimento clínico de crianças, em virtude das demandas e exigências desse sistema. Limites da confiabilidade e limitação do tempo são exemplos das modificações necessárias de acordo com as falas dos especialistas em saúde. A limitação do tempo é uma constatação, por sentirem-se pressionados a realizar uma escuta que não respeita a criança integralmente de acordo com suas necessidades. Por outro lado, os processos judiciais são lentos, aumentando a ansiedade e preocupação da criança.

Os profissionais da área da saúde salientaram que o seu papel não é de investigador policial ou de inquiridor, porém essa escuta supõe o objetivo de fornecer informaçóes importantes ao juiz que julgará o caso. Combinar com a criança que aquilo que for importante para sua proteção será comunicado aos órgãos de proteção da criança e do adolescente foi mencionado pelos profissionais da área da saúde, como registra a afirmação da profissional:

[...] Tem que assim, explicar para ela que o que ela tá conversando comigo vai sim poder ser utilizado pra além dessa conversa entre nós, né. (Psicóloga).

Outro problema percebido, não somente pelos profissionais da Área da Saúde, mas também pelos Operadores do Direito, é a falta de agilidade nos processos judiciais. Esses processos, via de regra, costumam se estender por vários anos. As testemunhas e/ou os envolvidos são chamados várias vezes para depor. Para a criança que sofreu abuso sexual isso pode ser penoso, prejudicial e até mesmo tornar-se sem sentido, dado o tempo decorrido, como se observa neste exemplo:

[...] ele está solto e a coisa está rolando ainda, ele não teve um julgamento final ainda, né. O Juiz tem dúvidas se ocorreu mesmo o abuso. (Psicóloga). 
De acordo com a literatura revisada, em diferentes momentos e contextos, as crianças são chamadas para repetir sua versão, que geralmente é confrontada com a versão do agressor que, por vezes, é ouvido ou questionado na presença da criança, repassando a responsabilidade total a ela, gerando sua exposição ou uma não proteção (Brito, Ayres \& Amendola, 2006; Daltoé-Cezar, 2007; Dobke, 2001). Conforme Sanderson (2005), a criança sente-se culpada inadequadamente, o que gera riscos para seu desenvolvimento e para a validade do seu testemunho, pois, dependendo como a inquirição for realizada, ela pode retirar a acusação da violência sofrida (Azambuja, 2006; Daltoé-Cezar, 2007; Dobke, 2001). De acordo com a legislação brasileira, se a criança não verbalizar o abuso ou se evidenciar alguma contradição em suas palavras e manifestações, o abuso não é considerado real, e a experiência da criança é rejeitada.

\subsection{Importância do trabalho interdisciplinar}

Os entrevistados consideram que não basta um profissional capacitado para atender a criança vítima de abuso sexual. A interdisciplinaridade possibilita uma maior complexidade da interação e da intervenção necessária nesse tipo de violência. Talvez um grande campo de análise seja justamente o trabalho realizado em rede, já que, com diferentes conhecimentos e em distintos âmbitos de intervenção, os profissionais envolvidos na complexa trama do abuso intrafamiliar podem usufruir dos benefícios da socialização de informaçôes e de outros intercâmbios. $\mathrm{Na}$ concepção de escuta de todos os profissionais, de ambos os grupos, faz-se fundamental um trabalho interdisciplinar e interinstitucional:

[...] Eu falei em rede de profissionais, que são pessoas que possam estar trabalhando juntos, até porque são pessoas que podem ter um olhar diferente, [...] se a gente tiver outras pessoas com qualificação e com um olhar diferente pode estar ajudando a esclarecer um quebra-cabeça que, às vezes, é impossível de resolver sozinho (pediatra);

[...] Nós tínhamos um trabalho bem sintonizado eu precisava muito do trabalho dela, ela sendo profissional da área da psicologia, também do Ministério Público, a gente trabalhava sempre em intercâmbio. (promotora de Justiça).

$\mathrm{Na}$ prática, segundo os participantes da pesquisa, existem lacunas ou dificuldades na formação pessoal e profissional de cada técnico, de distintas áreas do conhecimento, ao manejar os casos de abuso sexual intrafamiliar, o que pode frustrar a equipe de trabalho. Essas lacunas dizem respeito, 
especialmente, à falta de comunicação e parcerias entre os serviços que compõem a rede de proteção e à falta de apoio, estrutura e investimentos nos espaços físicos e no corpo técnico das equipes formadas, como nos explicam os participantes:

[...] O interdisciplinar tem que ser coordenado com diálogo, com reuniōes periódicas, avisar o que está fazendo, essas coisas. (promotora de justiça);

[...] Ainda é difícil a prática. A gente trabalha com muitas vaidades, com algum corporativismo, que são coisas que eu acho que interferem nisso. (assistente social);

[...] Eu trabalho em um time, em conjunto, elas são mais acolhedoras, mais receptivas, coisa que eu não sou. (juiz da infância e juventude).

Essas idéias concebidas pelos profissionais estão amparadas pela teoria, que aponta para a necessidade de distintas áreas atuando em conjunto. Equipes interdisciplinares são requeridas, que possam funcionar em rede por meio do diálogo e das complementaridades dos distintos profissionais e diferentes conhecimentos (Aded, Dalcin, Moraes \& Cavalcanti 2006; Habigzang, Azevedo, Koller \& Machado, 2006; Pfeiffer \& Salvagni, 2005).

Conforme o que foi exposto pelos participantes, nas diferentes áreas de atuação e de distintas se formas evoluiu, principalmente no que diz respeito à realização do trabalho com a violência intrafamiliar e especialmente quanto ao abuso sexual de crianças e adolescentes. Porém entre o ideal de trabalho e os limites de uma engrenagem institucional, existem caminhos a serem percorridos ou trajetórias a serem adequadas à rede de proteção que se faz necessária para responder positivamente às demandas dessa escuta. E é principalmente nessa escuta que novas metodologias são requeridas, pois emergem das exigências do manejo interdisciplinar. Além disso, há a necessidade de se reformular as relações deste trabalho com crianças, que por vezes mostram-se assimétricas, como propõe esta entrevistada:

[...] O Sistema Judiciário deve se adaptar para fazer uma escuta diferenciada para a criança [...] deve ser uma escuta marcada pelo respeito, pelo olhar pra criança [...] uma criança que sofre esse tipo de violência é algo com que ela não está habituada, ela tá chegando porque foi desrespeitada, não foi considerada, não foi olhada pela família. (psicóloga). 


\section{Considerações finais}

Há uma lacuna importante entre a idealização de um trabalho adequado com crianças vítimas de abuso sexual e aquilo que se tem como realidade na prática diária dos profissionais. Nas duas esferas profissionais investigadas, percebe-se que há reconhecimento acerca das limitações no atendimento dessa demanda peculiar. Parece ser reconhecido que os profissionais da área da saúde detêm melhores condições de realizar a escuta da população infantil, pela formação e experiência que têm. $\mathrm{Na}$ formação desses profissionais, encontra-se a preocupação com o mundo interno da criança, com seu estado emocional.

Outras dificuldades se evidenciam quando o despreparo dos profissionais aponta para as questões de formação, manejo e conduta nos casos atendidos e para outros fatores que contribuem para inadequações na realização do trabalho com esse tipo de demanda, já que apontam para a própria lei, na esfera do Judiciário, tem que a escuta da criança é vista como concretização de provas. $\mathrm{O}$ enfoque interdisciplinar, enriquecedor conforme o ponto de vista dos participantes, muitas vezes se perde em função da rede de proteção que deveria acolher e dar conta do trabalho com essas crianças, mas que tem inúmeras tramas falhas, pois depende do diálogo e da coesão do grande grupo ou equipe envolvida.

Retomando o objeto deste estudo, constata-se que está presente, nas concepções dos profissionais entrevistados, o reconhecimento da complexidade e especificidade do abuso sexual intrafamiliar. Pode ser ressaltado que essa forma de abuso sempre será difícil de ser identificada e trabalhada em virtude do vínculo ambivalente existente entre o agressor e a criança. Essa mesma complexidade desafia permanentemente todos aqueles que lidam com tais situações no âmbito do Judiciário, fazendo com que se sintam despreparados em muitos momentos. Isso leva a buscar continuamente o aprimoramento profissional, o que é atestado pela busca significativa de formação continuada, inclusive no nível de pós-graduação.

Constata-se também, de acordo com os dados analisados, que pode haver uma tensão e, ou, dissociação entre as necessidades da criança e as demandas do Judiciário. Entretanto é importante que se busque um equilíbrio entre essas dimensóes e essa busca está presente na experiência e nas concepçóes dos entrevistados. Os participantes dos dois grupos de profissionais apresentaram algumas diferenças e limitações.

Para uma escuta adequada, os operadores do Direito necessitam conhecer mais sobre o modo de funcionar da criança e suas particularidades, suas 
formas de comunicação. Profissionais da Saúde precisam conhecer melhor o ECA para compreender quais são os direitos da criança e de que forma eles podem beneficiá-las.

O equilíbrio entre as necessidades da criança e as demandas do Sistema de Justiça requer um trabalho interdisciplinar que promova e sustente a garantia dos direitos da criança e o seu atendimento adequado no âmbito do Judiciário. A necessidade e importância da interdisciplinaridade foram amplamente salientadas pelos entrevistados. Se há lacunas nesse trabalho, também existem muitas experiências positivas que servem de base ou suporte para a formação dos profissionais.

As categorias finais foram as mesmas para os dois grupos de profissionais investigados. Compreende-se que isso se deve à ampla e consistente experiência dos participantes, ao fato de eles trabalharem em equipes multidisciplinares ou interdisciplinares, deparando-se com o mesmo fenômeno em suas atividades profissionais e apresentarem experiências similares na escuta da criança no âmbito do Judiciário.

\section{Referências}

Aded, N. L. O. de, Dalcin, B. L. G. S., Moraes, T. M. \& Cavalcanti, M. T. (2006). Abuso sexual em crianças e adolescentes: Uma revisão de 100 anos de literatura. Revista de Psiquiatria Clínica, 33 (4), 204-213.

Aleixo, R. C. (2008). A extração da verdade e as técnicas inquisitórias voltadas para a criança e o adolescente. Psicologia Clínica, 20 (2), 103-111.

Alonso-Quecuty, M. L. (1999). Evaluación de la credibilidad de las declaraciones de menores víctimas de delitos contra la liberdad sexual. Papeles del Psicólogo, 73, 36-40.

Araújo, M. F. (2002). Violência e abuso sexual na família. Psicologia em Estudo, 7(2), 3-11.

Azambuja, M. P. R. (2005). Violência doméstica: reflexões sobre o agir profissional. Psicologia: Ciência e Profissão, 25 (1), 4-13.

Azambuja, M. R. F. (2006). Violência sexual intrafamiliarinterfaces com a convivência familiar, a oitiva da criança e a prova da materialidade. Revista dos Tribunais, 95 (852), 425-446. 
Azevedo, E. C. de. (2001). Atendimento psicanalítico a crianças e adolescentes vítimas de abuso sexual. Psicologia: Ciência e Profissão, 21 (4), 66-77.

Barbosa, G. F. (2007). Segredo de família e o tratamento psicanalítico. In: M.B. Dias (org.). Incesto e alienação parental. (pp. 93-100). São Paulo: Revista dos Tribunais.

Benfica, F. \& Souza, J. (2002). A importância da perícia na determinação da materialidade dos crimes sexuais. Revista do Ministério Público do Rio Grande do Sul, 46, 173-186.

Brito, L. M. T. (2008) Diga-me agora...: o depoimento sem dano em análise. Psicologia Clínica, 20 (2), 113-125.

Brito, L., Ayres, L. \& Amendola, M. (2006). A escuta de crianças no sistema de Justiça. Psicologia \& Sociedade, 18(3), 68-73.

Cesca, T. B. (2004). O papel do psicólogo jurídico na violência intrafamiliar: possíveis articulações. Psicologia \& Sociedade, 16 (3), 41-46.

Colacique, M. A. M. (2006). Intervenção psicológica no sofrimento psíquico de criança e adolescente envolvidos com processos em tramitação na justiça. Tese de doutorado não publicada, Universidade de São Paulo, Brasil.

Conselho Federal de Psicologia. (2008a). Conheça a manifestação do Conselho sobre o PL que trata do depoimento sem dano. Disponível em <http://www. pol.org.br/pol/cms/ pol/ noticias/noticia_080409_932.html>. Acesso em: 31 ago. 2009.

Conselho Federal de Psicologia. (2008b). CFP é contra depoimento sem dano. Jornal do Federal, 89,10-10.

Daltoé-Cezar, J. A. (2007). Depoimento sem dano: uma alternativa para inquirir crianças e adolescentes nos processos judiciais. Porto Alegre: Livraria do Advogado.

De San Lazaro, C. (1995). Making pediatric assessment in suspected sexual abuse a therapeutic experience. Archives of Disease in Childhood, 73 (2), 174176.

Dias, M. B. (2007). Incesto e o mito da família feliz. In: M.B. Dias (org.). Incesto e alienação parental. (pp. 17-49). São Paulo: Revista dos Tribunais. 
Dobke, V. (2001). Abuso sexual: a inquirição das crianças, uma abordagem interdisciplinar. Porto Alegre: Ricardo Lenz.

Ferreira, A. L. (2005). Acompanhamento de crianças vítimas de violência: desafios para o pediatra. Jornal de Pediatria, 81 (5), 173-180.

Ferreira, A. L. \& Schramm, F. R. (2000). Implicações éticas da violência doméstica contra a criança para profissionais de saúde. Revista de Saúde Pública, 34 (6), 658-665.

Ferreira, M. H. M. (2007). Memórias falsas ou apuração inadequada. In: M. B. Dias (org.). Incesto e alienação parental. (pp.140-145). São Paulo: Revista dos Tribunais.

Ghetti, S. Alexander, K. \& Goodman, G. (2002). Legal involvement in child sexual abuse cases: consequences and interventions. International Journal of Law and Psychiatry, 25, 235-251.

Goodman, G. S., Bottoms, B. L., Rudy, L., Davis, S. L. \& Schwartz-Kenney, B. M. (2001). Effects of past abuse experience on children's eyewitness memory. Law and Human Behavior, 25 (3), 269-298.

Habigzang, L. F., Azevedo, G. A., Koller, S. H. \& Machado, P. X. (2006). Fatores de risco e proteção na rede de atendimento a crianças e adolescentes vítimas de violência sexual. Psicologia: Reflexão e Crítica, 19 (3), 379-386.

Heiman, M. L., \& Ettin, M. F. (2001). Harnessing the power of the group for latency-aged sexual abuse victims. International Journal of Group Psychotherapy, $51(2), 265-281$.

Juárez-López, J. R. (2004). El menor como testigo: fundamentos y técnicas. Manuscrito não-publicado, Universidade de Girona, Espanha.

Junqueira, M. F. da S. (2002). Violência e abuso sexual infantil: uma proposta clínica. Cadernos de Psicanálise, 18 (21), 209-226.

Lamb, M. E., Sternberg, K. J., Orbach, Y., Esplin, P., Stewart, H. \& Mitchell, S. (2003). Age differences in young children's responses to open-ended invitations in the course of forensic interviews. Journal of Consulting and Clinical Psychology, 71 (5), 926-934.

Morales, A. E. \& Schramm, F. R. (2002). A moralidade do abuso sexual intrafamiliar em menores. Ciência \& Saúde Coletiva, 7 (2), 265-273. 
Pfeiffer, L. \& Salvagni, E. P. (2005). Visão atual do abuso sexual na infância e adolescência. Jornal de Pediatria, 81 (supl. 5), 197-204.

Rovinski, S. L. R. (2004). Fundamentos da perícia psicológica forense. São Paulo: Vetor.

Sanderson, C. (2005). Abuso sexual em crianças. São Paulo: M. Books do Brasil.

Ward, O. A. W. (2003). Trauma por maltrato y revictimización en menores. Medicina Legal de Costa Rica, 20 (2), 27-46. 